\title{
Are Green Products Over-Priced?
}

\author{
By Philippe Mahenc* \\ LERNA-INRA, Manufacture des Tabacs, \\ 21 Allée de Brienne \\ 31000 Toulouse FRANCE \\ Email: mahenc@univ-perp.fr
}

October 17, 2006

\begin{abstract}
This article investigates conditions under which high prices, in conjunction with low levels of pollution, signal environmentally clean products. It is shown that, when consumers cannot ascertain the environmental performance of products, the price must be distorted
\end{abstract}

*LERNA-INRA, Université Toulouse 1 and GEREM, Université de Perpignan. I wish to thank one anonymous referee for helpful comments. 
upward to signal a clean product. A clean producer saves less from emitting pollution and so raises price and restricts output with less reluctance than does a dirty producer. The theoretical result of overpricing is consistent with the evidence that "green" products receive higher prices than conventional products. However, optimistic prior beliefs of high environmental performance may cause signaling to fail. Keywords: Environmental Performance, Experience Good, Green Product, Pollution, Quality, Signaling.

JEL Code: D42, D82, L15, Q50. 


\section{Are Green Products Over-Priced?}

This paper has not been submitted elsewhere in identical or similar form, nor will it be during the first three months after its submission to the Publisher.

\section{Introduction}

Green products are generally priced higher than conventional products. Moreover, the prices charged by green producers appear to be far higher than explainable by costs or market power. This paper provides an explanation for such price distortions based on asymmetric information.

It is likely that consumers find it difficult to ascertain the environmental performance of a product. Green claims made by producers, such as "organically grown", "biodegradable" or "packaging containing at least $50 \%$ recycled material", are not always verifiable, hence do not always convey much direct information about the environmentally friendliness of a product (see Cason and Gangadharan (2002)). Moreover, consumers can hardly be as well informed as producers on their environmental technology. This is particularly true in those cases where new products promise to reduce polluting emissions, such as products from sustainable agriculture ${ }^{1}$, reformulated gasoline (see the

\footnotetext{
${ }^{1}$ According to Tietenberg (2000, p. 238), "at present, $1 \%$ of U. S. produce is organically grown and experts in the fields predict as much as $10 \%$ by the end of the century".
} 
case of ARCO in Innes and Bial (2002)) and, more generally, all the products claiming that they are "green". In the presence of asymmetric information about the environmental performance of a product, the price of the product itself has a role to play in releasing information about the polluting feature of this product. The signaling activity of imperfectly competitive producers is potentially a third source of market failure adding to those pointed out by Buchanan (1969), due respectively to the externality and excessive market power.

This paper argues that the price of green products must be distorted upward to signal that they are cleaner than conventional products. Such a prediction appears to be consistent with recent observations ${ }^{2}$. Due to overpricing, output and pollution which are already restricted by the exercise of market power, are even further restricted for the sake of signaling environmental friendliness. One caveat to the overpricing result is that prices may fail to fully reveal information on the environmental performance of a product. This is shown to arise when consumers, before purchase, attach a bigger probability to the producer being clean.

A model is developed in which a producer with market power is assumed

\footnotetext{
${ }^{2}$ According to the European Commission, "almost all organic products receive a higher price than conventional products" in the European Union. For instance, the figures for Sweden given by the European Commission show that the premium on organic products prices for the crop sector is always above $50 \%$ in 1998 (http://europa.eu.int/comm/agriculture/qual/organic). Nimon and Beghin (1999) provides empirical evidence on the existence of price premiums in the U. S. green apparel markets.
} 
to have superior knowledge of the environmental performance of his product, while consumers imperfectly know to what extent the product is environmental friendly. Furthermore, consumers are assumed to have some willingness to pay to eliminate the pollution attached to the product they purchase. Hence, the present work is related to environmental models that consider environmental friendliness as a quality attribute of a product (Arora and Gangopadhyay ((1995), Cremer and Thisse (1999), Bansal and Gangopadhyay (2003)).

The intuition underlying the prediction of overpricing in markets for green products is the following. The producer of an environmentally clean good has an incentive to reveal his information to consumers: confronted with consumers who care about environment, the producer has every reason to persuade them that his product is clean. By contrast, the producer of an environmentally dirty product has an incentive to trick consumers into believing he is selling an environmentally clean product. These are circumstances favorable to the emergence of a signal. Paraphrasing Spence (1976), the signal will be effective provided that it is unprofitable for a producer of a dirty product to imitate it. The main reason is that a cleaner producer has higher production costs and so he benefits less from producing and saves less from emitting pollution. Hence, a clean producer is more willing to raise price and reduce pollution than is a dirty producer. A clean producer may then charge a price that exceeds the full information price to identify himself. At 
the same time, he pollutes less than he would under full information.

However, the existence of separating equilibria does not dismiss pooling equilibria in which prices conceal information on environmental performance. The logic of Undefeated Equilibrium (Mailath, Okuno-Fujiwara and Postlewaite (1993)) is applied to select among equilibria. As a result, separation is achieved if consumers do not estimate environmental performance too optimistically before purchase. The only undefeated equilibria are pooling when consumers have high prior beliefs that the producer is clean, thus prices are uninformative in such a case. It turns out that pooling equilibrium prices are distorted compared to full information prices regardless of the environmental performance of the producer.

There is some analogy between the result that prices signaling high environmental performance are biased upward and the familiar result in industrial organization that high prices signal high product quality (Milgrom and Roberts (1986), Tirole (1988) on pages 110-111, Bagwell and Riordan (1991)). Clearly, both results are driven by the fairly close assumptions that a cleaner product in the former case and a higher-quality product in the latter case are more costly to produce. However, a classical price signaling model of quality could not apply to the study of green markets without further extension. As emphasized by Kotchen (2006), green goods are impure public goods that combine a private good with a positive externality (environmental quality). Models à la Milgrom-Roberts do not explicitly take into 
account externalities since consumers have fixed willingness to pay for given assessments of product quality and there is no linkage between quality and the sales volume. In contrast, the present model allows for the possibility that consumers' willingness to pay for a product is affected by the level of pollution linked with the total amount of sales. Moreover, green consumers are willing to pay more for a cleaner product. The fact remains that the clean producer loses a lower profit margin per consumer from an increase in price than does the dirty producer.

Furthermore, a standard result in the literature of industrial organization is that high and low-quality producers always separate themselves in equilibrium. The equilibrium selection criterion employed here provides the novel insight that pooling equilibrium prices prevail over separating equilibrium prices when consumers optimistically overestimate environmental performance. In such a case, the dirty producer distorts his price upward in order to be thought of as clean, which lifts up consumers' willingness to pay for his product. The reason why the pooling strategy is successful is that high prior beliefs that the producer is clean increases the opportunity cost of fully revealing information for the clean producer.

The paper is organized in four sections including the present introduction. Section 2 presents the basic model under complete information. The case of asymmetric information is analyzed in Section 3. Conclusions are drawn in Section 4 . 


\section{The basic model}

Consider a monopolist who produces an amount $q$ of a good that, once consumed, generates a level $e$ of polluting emissions. To simplify the analysis, emissions will be assumed to be strictly proportionate to output, i. e., $e=\theta q$, where $\theta>0$ is an index for the environmental performance of the product. This is a standard assumption in the environmental literature (see, for example, Baumol and Oates (1988, p. 222), Kolstad (2000, p. 125), Innes and Bial (2002)), which corresponds to measuring the release of pollutants such as $\mathrm{NO}_{x}, \mathrm{CO}, \mathrm{SO}_{2}$, per unit of product. Although consumers do not directly observe the environmental performance of the product, they do know that it is one of two possible levels, $\underline{\theta}$ if the product is clean and $\bar{\theta}$ if it is dirty, with $\underline{\theta}<\bar{\theta}$. The technological process is described by the cost function $c(q, \theta)=c(\theta) q$, with $c^{\prime}(\theta)<0$ and $c^{\prime \prime}(\theta)>0$ : production costs depend upon the environmental performance of the product and pollution abatement is increasingly costly. The assumption on $c($.$) dependant on \theta$ will prove to be crucial for the existence of separating equilibria in the asymmetric information case.

Consumers are assumed to be heterogeneous in their basic willingness to pay for the good but homogeneous in their valuations of the damage caused by pollution. Specifically, a consumer of type $r$ has a willingness to

pay $r-d(e)$ for one unit of the good, where $d(e)$ is the individual damage 
generated by a level $e$ of pollution. One expects consumers to be harmed by pollution even if they don't buy the good, albeit to a lesser degree. Let $d_{0}(e)$ be the individual damage in such a case or, equivalently, the willingness to pay for reducing the global impact of pollution on the environment. The difference $d(e)-d_{0}(e)$ represents the personal impact of pollution on health or utility, as when ingesting polluted air and water, eating food containing chemical, exposing the organism to toxic substances through consumption ${ }^{3}$ or losing enjoyment from a natural vista shrouded in smog. Let us simplify by assuming that $d(e)-d_{0}(e)=\beta e$, where $\beta>0$ measures the degree of consumers' awareness to be harmed when consuming the good. Hence, consumers care about the environment and so they are willing to pay a higher price for a product that generates less environmental harm.

The basic willingness to pay, $r$, is assumed to be uniformly distributed along $(0, R]$, with $R>c(\underline{\theta})$. A consumer of type $r$ derives a surplus $r-d(e)-p$ from purchasing the good at price $p$, and $-d_{0}(e)$ if he does not buy. Letting $\widetilde{r}(p, \theta)$ denote the marginal consumer who is indifferent between buying or not, $\widetilde{r}(p, \theta)$ solves the following equation for $r$ :

$$
r-\beta \theta(R-r)-p=0
$$

\footnotetext{
${ }^{3}$ According to Tietenberg (2000, p. 493), "some 55000 of the potential substances that could prove toxic are in active use". Pesticides for instance are toxic by design, some chemicals are potentially serious causes of chronic illness, food additives pose a serious and immediate threat to health since they are ingested.
} 
Hence, a cleaner producer faces potential customers with higher willingness to pay for his product. Note that in a classical price signaling model of quality, consumers' willingness to pay would be taken to be fixed, which could be captured here by replacing $R-r$ by 1 for example. Moreover, under complete information about $\theta$, the producer's demand is represented by the following demand curve

$$
R-\widetilde{r}(p, \theta)=\frac{R-p}{1+\beta \theta} .
$$

Note that, for this class of demands, price elasticity is $\eta(p) \equiv \frac{p}{R-p}$, hence does not directly depend on environmental performance. As consumers have incomplete knowledge as to whether the product is clean or dirty, they must rely on their beliefs about the product environmental performance when taking their purchase decisions. Observing $p$, consumers try to infer some information about environmental performance and update their beliefs. Then, given these beliefs, consumers maximize their expected payoffs. Let $\mu(p): \mathbb{R}^{+} \rightarrow[0,1]$ denote the consumers' posterior belief that the product is clean when the price is $p$. If consumers assign probability $\mu=\mu(p)$ to the clean product, then $\theta_{\mu} \equiv \mu \underline{\theta}+(1-\mu) \bar{\theta}$ is the consumers' perception of the product environmental performance upon seeing $p$. Under asymmetric 
information, the producer's demand is represented by the demand curve

$$
D(p, \mu) \equiv \frac{R-p}{1+\beta \theta_{\mu}}
$$

Note that $D(p, \mu)$ is an increasing function of $\mu$. Thus, the producer prefers consumers' beliefs about environmental performance to be optimistic, i. e., a high $\mu$, regardless of his true environmental performance.

The profit of a producer selling a product of true environmental performance $\theta$ at a price $p$, that is believed to be clean with probability $\mu$, is given by $\pi(p, \theta, \mu) \equiv(p-c(\theta)) D(p, \mu)$. This is a strictly concave function with a single maximum at $\frac{R+c(\theta)}{2}$, which yields a maximized profit of $\frac{(R-c(\theta))^{2}}{4\left(1+\beta \theta_{\mu}\right)}$. Let $p^{*}(\theta)$ denote the profit maximizing price. The benchmark case of complete information is stated as follows.

Lemma 1: Under complete information, the monopolist charges the price $p^{*}(\theta)=\frac{R+c(\theta)}{2}$ satisfying $\frac{p^{*}(\theta)-c(\theta)}{p^{*}(\theta)}=\frac{1}{\eta\left(p^{*}(\theta)\right)}$.

This is the standard result that the Lerner index is equal to the inverse of the price elasticity of demand. As $\eta\left(p^{*}(\theta)\right)=\frac{R+c(\theta)}{R-c(\theta)}$ in the present case, it can be checked that the cleaner the product, the more elastic the demand at the profit maximizing price.

Let $\mu_{0}$ be the probability assigned by consumers to the product being clean prior to purchase. This parameter summarizes all the information that is publicly available in public disclosure programs and also unstruc- 
tured information (see Foulon, Lanoie and Laplante (2002)), hence describes consumers' misinformation about the product environmental performance before purchase: if $\mu_{0}$ is such that $\theta_{\mu_{0}}$ is higher than the true index, then the product environmental performance is overestimated. It will be shown that depending on the value of $\mu_{0}$, the producer's optimal choice may be, either to fully reveal information on environmental performance through separating prices, or to conceal information through pooling prices.

The producer's problem is to maximize his profit with respect to $p$, given consumers' updated beliefs. The strategies must form a perfect Bayesian equilibrium. Denoting by $\varphi(\underline{\theta})$ and $\varphi(\bar{\theta})$ the equilibrium prices for respectively the clean producer and the dirty producer, the set of strategies and beliefs $(\varphi(\underline{\theta}), \varphi(\bar{\theta}), \mu(p))$ is an equilibrium if the following two conditions are satisfied

- Optimality condition.

For $\theta=\underline{\theta}, \bar{\theta}, \varphi(\theta)=\arg \max _{p} \pi(p, \theta, \mu)$.

- Bayes' consistency of beliefs.

If $\varphi(\bar{\theta}) \neq \varphi(\underline{\theta})$, then $\mu(\varphi(\bar{\theta}))=0$ and $\mu(\varphi(\underline{\theta}))=1$. If $\varphi(\bar{\theta})=\varphi(\underline{\theta})$, then $\mu(\varphi(\bar{\theta}))=\mu_{0}$.

The latter condition requires consumers' posterior beliefs about $\theta$ to be obtained from their prior beliefs by using Bayes' rule along the equilibrium path. This leads to distinguish between separating equilibria (in which clean 
and dirty producers choose different prices) and pooling equilibria (in which the producer's price is independent of his environmental performance). As usual, beliefs-updating is arbitrary off the equilibrium path. Attention will be restricted to pure-strategy equilibria.

\section{The asymmetric information case}

Let us now analyze the producers' behavior under asymmetric information. He must take into account how his choice of price influences consumers' inferences.

\subsection{Separating and pooling equilibrium prices}

To prove the existence of separating equilibria, it is useful to check that the following three conditions on $\pi(p, \theta, \mu)$ are satisfied. Subscripts denote partial derivatives.

1. $\pi_{\mu}>0$.

2. $\pi_{\theta p}=\frac{c^{\prime}(\theta)}{1+\beta \theta_{\mu}}<0$.

3. $\mathcal{R} \equiv-\pi_{\mu}(p, \theta, \mu) / \pi_{p}(p, \theta, \mu)$ is a strictly decreasing function of $\theta$.

Condition 1 directly follows from (3) and indicates that profit increases in the perceived environmental cleanness. A straightforward consequence of 
condition 1 is that $\mu=0$ is the worst inference consumers may draw, from the producer's point of view, regardless of his true environmental performance. Condition 2 states that the profitability of changing price increases in the environmental cleanness. Condition 3 is the familiar single crossing property which means here that $\mathcal{R}$, i. e., the marginal rate of substitution between price and perceived performance, is a decreasing function of $\theta$. Indeed, straightforward calculations give that $\mathcal{R}_{\theta}=\frac{c^{\prime}(\theta) D(p, \mu) D_{\mu}(p, \mu)}{\pi_{p}(p, \theta, \mu)^{2}}<0$. When the product becomes cleaner, the producer is willing to charge a higher price for a given increase in consumers' beliefs that the product is actually cleaner. Clearly, if it were assumed that $c^{\prime}(\theta)=0^{4}$ or $D_{\mu}(p, \mu)=0$, the singlecrossing property would not be satisfied. Thus, the existence result in the lemma below crucially hinges on both assumptions that, first, there is a linkage between environmental performance and product efficiency, and second, consumers' willingness to pay for the product changes as perceived quality changes. Moreover, the overpricing result requires simultaneously that green goods are more costly to produce and producers prefer to be thought of as green.

From Mailath (1987), conditions 1-3 are necessary and sufficient for the existence of separating equilibria.

\footnotetext{
${ }^{4}$ As suggested by one referee, this assumption would be consistent with end-of-pipe cleanup technologies, where benefits and costs are purely environmental.
} 
Lemma 2: Under conditions 1-3, there exists separating equilibrium prices such that $\varphi(\bar{\theta})=p^{*}(\bar{\theta})$ and $\varphi(\underline{\theta})>p^{*}(\underline{\theta})$.

It is possible for producers to signal their environmental friendliness with prices that raise with the environmental performance of products. As usual, the signaling strategy is socially costly, which means here that the clean producer distorts his price upward relative to what would prevail under full information. Overpricing is the actual means of separation because the clean producer loses a lower profit margin per consumer from an increase in price than does the dirty producer. Consequently, the clean producer pollutes less than under full information to signal that his product is clean.

A well-known feature of the perfect Bayesian equilibrium concept is that it usually allows the existence of a number of equilibria. In the present situation, there are infinitely many separating equilibrium prices at which the clean producer can profitably distinguish himself, whereas the full information price is the only one to signal the dirty product. Let $\pi_{\underline{\theta}}$ and $\pi_{\bar{\theta}}$ denote the equilibrium profits for respectively the clean producer and the dirty producer. When environmental performance is perfectly identified, the dirty producer earns more by charging his full information price $p^{*}(\bar{\theta})=\frac{R+c(\bar{\theta})}{2}$ than any other price. Thus, $\varphi(\bar{\theta})=\frac{R+c(\bar{\theta})}{2}$ in any separating equilibrium. On the other hand, when the dirty producer is thought to be clean after choosing a price $p$, he faces a demand $\frac{R-p}{1+\beta \theta}$ and has a mimicking profit $\pi(p, \bar{\theta}, 1)=(p-c(\bar{\theta}))\left(\frac{R-p}{1+\beta \underline{\theta}}\right)$. Furthermore, if the clean producer quotes 
a price $p$ on the basis of which he is believed to sell a dirty product, then he makes a profit $\pi(p, \underline{\theta}, 0) \equiv(p-c(\underline{\theta}))\left(\frac{R-p}{1+\beta \bar{\theta}}\right)$. Maximizing this profit by charging the price $\frac{R+c(\underline{\theta})}{2}$, would yield a profit of $\frac{(R-c(\theta))^{2}}{4(1+\beta \bar{\theta})}$, which can be interpreted as the opportunity cost to signal cleanness.

To achieve separation, the clean producer must set a price $\varphi(\underline{\theta})$ that satisfies the two following conditions:

$$
\begin{aligned}
& \pi(\varphi(\underline{\theta}), \bar{\theta}, 1) \leq \frac{(R-c(\bar{\theta}))^{2}}{4(1+\beta \bar{\theta})} . \\
& \pi(\varphi(\underline{\theta}), \underline{\theta}, 1)>\frac{(R-c(\underline{\theta}))^{2}}{4(1+\beta \bar{\theta})} .
\end{aligned}
$$

Condition (4) ensures that the dirty producer prefers his own separating price $\varphi(\bar{\theta})$ to $\varphi(\underline{\theta})$. Condition (5) guarantees that the clean producer does not deviate to $\frac{R+c(\underline{\underline{\theta}})}{2}$, no matter what inferences consumers might draw from the observation of such a price. It will be denoted respectively by $\mathcal{P}_{1}$ the set of prices defined by condition (4) and by $\bar{p}$ the upper root solving the equality version of condition (5) (see Appendix 1 for more details). The constraint to choose a price in $\mathcal{P}_{1}$ distorts upward the price charged by the clean producer relative to the full information optimal price. Let $\mathcal{P}_{2}$ denote the interval of prices for which condition (5) is met.

Proposition 1: There exists a continuum of separating equilibrium prices such that $\varphi(\bar{\theta})=\frac{R+c(\bar{\theta})}{2}$ and $\varphi(\underline{\theta}) \in \mathcal{P}_{1} \cap \mathcal{P}_{2}$. 
In order to reveal his true environmental performance, the clean producer must choose $\varphi(\underline{\theta})$ in the set $\mathcal{P}_{1} \cap \mathcal{P}_{2}$, which is explicitly given in Appendix 2. As a result, the price signaling the clean product is higher than the full information price. In equilibrium, consumers infer the true environmental performance from observing price but they pay a signaling cost since the clean product is over-priced. This in turn reduces pollution relative to what would prevail under full information. The price can function as an effective signal of quality because the dirty producer finds it more costly to raise price than does the clean producer. To prove that his product is clean, the clean producer must pollute less than would be the case under full information.

The existence of separating equilibria does not dismiss pooling equilibria. Let $\varphi$ denote the uninformative price that is part of a pooling equilibrium. Since it is the same price charged by the producer, regardless of environmental performance, the consumers' posterior beliefs after observing the price $\varphi$ are the same as their prior beliefs. The monopolist earns $\pi\left(\varphi, \theta, \mu_{0}\right)$ if such a price does exist. To exist, it suffices that $\varphi$ satisfies the two following conditions:

$$
\pi\left(\varphi, \theta, \mu_{0}\right) \geq \frac{(R-c(\theta))^{2}}{4(1+\beta \bar{\theta})}, \theta=\underline{\theta}, \bar{\theta} .
$$

Any price yielding a profit in both states of nature, no lower than the right-hand side of (6) - that is, what the producer could get at best if he were thought to be dirty with certainty -, is a candidate for concealing information. 
Nevertheless, some pooling equilibrium prices are less plausible than others.

\subsection{Equilibrium selection}

To discard implausible equilibria, it is useful to apply the logic of Undefeated Equilibrium (UE) proposed by Mailath, Okuno-Fujiwara and Postlewaite (1993). Define $\pi_{\theta}^{*}$ and $\pi_{\theta}^{\#}$ as the equilibrium profits of the producer with index $\theta$ at prices $\varphi^{*}(\theta)$ and $\varphi^{\#}(\theta)$ respectively. Furthermore, let $\mu^{*}(p)$ be the posterior belief held after observing $p$, that sustains $\varphi^{*}(\theta)$ as an equilibrium. Following Mailath, Okuno-Fujiwara and Postlewaite (1993), the equilibrium involving the price $\varphi^{*}(\theta)$ survives the UE criterion, provided that there does not exist another equilibrium with $\varphi^{\#}(\theta)$ "defeating" the equilibrium with $\varphi^{*}(\theta)$, i. e.:

$$
\begin{aligned}
& \text { If } \varphi^{\#}(\bar{\theta})=\varphi^{\#}(\underline{\theta}), \\
& \text { then } \pi_{\theta}^{\#} \geq \pi_{\theta}^{*} \text { for } \theta=\underline{\theta}, \bar{\theta} \text { with one inequality strict and } \mu^{*}\left(\varphi^{\#}(\underline{\theta})\right) \neq \mu_{0} . \\
& \text { If } \varphi^{\#}(\bar{\theta}) \neq \varphi^{\#}(\underline{\theta}), \\
& \text { then } \pi_{\underline{\theta}}^{\#}>\pi_{\underline{\theta}}^{*}, \pi_{\bar{\theta}}^{\#} \leq \pi_{\bar{\theta}}^{*} \text { and } \mu^{*}\left(\varphi^{\#}(\underline{\theta})\right) \neq 1 .
\end{aligned}
$$

The existence of an equilibrium with $\varphi^{\#}(\theta)$ would induce the producer to 
deviate from $\varphi^{*}(\theta)$. Some persuasive arguments in favor of the UE criterion can be found in Mailath, Okuno-Fujiwara and Postlewaite (1993). In the present context, the logic of this refinement is parallel to a Pareto dominance argument in reference to the producer only. As the producer is potentially of two types, both of these types should not be wastefully competitive with themselves.

Proposition 2: All the separating equilibrium prices are defeated by the following pair of least-costly separating equilibrium prices:

- $\varphi(\bar{\theta})=\frac{R+c(\bar{\theta})}{2}$ for the dirty product,

- and $\varphi(\underline{\theta})=\bar{p}$ for the clean product.

From requirement (8), the separating equilibrium entailing the leastcostly signal defeats all the other separating equilibria. To prevent the dirty producer from mimicking, the clean producer must raise his price up to the level $\bar{p}$ that minimizes the loss of buyers resulting from the upward distortion. The signaling cost incurred by the clean producer is then measured by the profit differential $\frac{(R-c(\underline{\theta}))^{2}}{4(1+\beta \underline{\theta})}-\pi(\bar{p}, \underline{\theta}, 1)>0$, where $\frac{(R-c(\underline{\theta}))^{2}}{4(1+\beta \underline{\theta})}$ is the maximized full information profit when the product is clean. One can easily check from Appendix 3 that the upward distortion $\bar{p}-p^{*}(\underline{\theta})$ increases with both the profit margin of the dirty producer, namely $\frac{R-c(\bar{\theta})}{2}$, and the cost differential $c(\bar{\theta})-c(\underline{\theta})$ in favor of the dirty producer. Thus, signaling a clean product is easier when the dirty producer either has greater market power or a higher 
cost advantage.

Let us now return to the analysis of pooling equilibria. Letting the dirty producer mimic is costly for the clean producer: the profit differential relative to the full information situation is given by $\frac{(R-c(\underline{\theta}))^{2}}{4(1+\beta \underline{\theta})}-\pi\left(\varphi, \underline{\theta}, \mu_{0}\right)$. Moreover, requirement (8) imposes the further restriction on $\varphi$ :

$$
\pi(\bar{p}, \underline{\theta}, 1) \leq \pi\left(\varphi, \underline{\theta}, \mu_{0}\right)
$$

If inequality (9) holds, then the clean producer is better off with the pooling equilibrium price $\varphi$ than with the separating equilibrium price $\varphi(\underline{\theta})$. Since the dirty producer will also find it more profitable to imitate $\varphi$ than to reveal information, requirement (9) guarantees that the pooling equilibrium defeats the least-costly separating equilibrium in the sense of Mailath, Okuno-Fujiwara and Postlewaite (1993). In such a case, it is more plausible that information will not be revealed in equilibrium. Clearly, (9) will hold for sufficiently high values of $\mu_{0}$. More precisely, let $\bar{\mu}$ define the unique probability $\mu$ such that

$$
\pi(\bar{p}, \underline{\theta}, 1)=\frac{(R-c(\underline{\theta}))^{2}}{4\left(1+\beta \theta_{\mu}\right)} .
$$

The right-hand side of (10) is the maximum profit that the clean producer can make by holding back information, when consumers believe the 
product to be clean with probability $\mu$. This corresponds to the opportunity cost of fully revealing environmental performance for the clean producer. Interestingly enough, this opportunity cost increases with $\mu$ because a higher belief that the product is clean lifts up the willingness to pay of uninformed consumers. The critical value $\bar{\mu}$ is the level of beliefs such that the clean producer is indifferent between signaling his environmental performance at some cost and concealing information about it. If $\mu_{0}$ is strictly lower than $\bar{\mu}$, then inequality (9) is violated regardless of the uninformative price $\varphi$ considered. Consequently, it is more plausible that information will be revealed in equilibrium. The result is reversed for values of $\mu_{0}$ higher than $\bar{\mu}$. Then, the producer will prefer to conceal his private information about the product environmental performance.

Furthermore, recall that $\frac{(R-c(\theta))^{2}}{4\left(1+\beta \theta_{\mu_{0}}\right)}$ is the profit made by the producer of type $\theta$ when he is perceived to be clean with probability $\mu_{0}$ and optimizes accordingly. To make such a profit, the producer must charge the price $p^{*}(\theta)=\frac{R+c(\theta)}{2}$ which does not depend on consumers' beliefs. Thus, whatever $\mu_{0}$, the producer of type $\theta$ maximizes his profit at $\frac{R+c(\theta)}{2}$. As $p^{*}(\bar{\theta})<p^{*}(\underline{\theta})$, we have, firstly, that, for all $p \in\left[0, p^{*}(\bar{\theta})\right)$,

$$
\pi\left(p, \theta, \mu_{0}\right)<\pi\left(p^{*}(\bar{\theta}), \theta, \mu_{0}\right), \theta=\underline{\theta}, \bar{\theta}
$$


and secondly, that, for all $p \in\left(p^{*}(\underline{\theta}), R\right]$,

$$
\pi\left(p, \theta, \mu_{0}\right)<\pi\left(p^{*}(\underline{\theta}), \theta, \mu_{0}\right), \theta=\underline{\theta}, \bar{\theta} .
$$

Assertion (11) implies that all the pooling equilibria involving a price strictly lower than $p^{*}(\bar{\theta})$ and a prior probability $\mu_{0} \in(\bar{\mu}, 1)$, are defeated by the pooling equilibrium involving the price $p^{*}(\bar{\theta})$ and the prior probability $\mu_{0}$. Moreover, assertion (12) implies that all the pooling equilibria involving a price strictly higher than $p^{*}(\underline{\theta})$ and a prior probability $\mu_{0} \in(\bar{\mu}, 1)$, are defeated by the pooling equilibrium involving the price $p^{*}(\underline{\theta})$ and the prior probability $\mu_{0}$. Finally, Proposition 3 presents all the equilibria surviving the refinement criterion proposed by Mailath, Okuno-Fujiwara and Postlewaite (1993).

\section{Proposition 3:}

1. If $\mu_{0} \leq \bar{\mu}$, then separation is achieved with the pair of undefeated separating equilibrium prices $\varphi(\bar{\theta})=\frac{R+c(\bar{\theta})}{2}$ and $\varphi(\underline{\theta})=\bar{p}$.

2. If $\mu_{0}>\bar{\mu}$, then a continuum of undefeated equilibria exists, which is characterized by pooling at any price inside $\left[p^{*}(\bar{\theta}), p^{*}(\underline{\theta})\right]$.

When consumers have low prior beliefs that the product is clean, the dirty producer finds it more difficult to lift up their willingness to pay for the product by raising price in an attempt to act the same way as the clean 
producer. In such a case, the clean producer can fully reveal information about environmental performance by distorting price above the full information level. At the same time, the pollution level that is generated by the clean producer falls below the full information level.

On the other hand, optimistic prior beliefs of high environmental performance make separation doubtful because signaling the true environmental performance has become more costly than accepting mimicry for the clean producer. High prior beliefs that the product is clean enhance consumers' willingness to pay for the product and decrease the cost of mimicking for the dirty producer. He can more easily charge the same price as the clean producer since consumers are more inclined to think that the product is clean. The dirty producer can influence consumers' inferences by raising price because their willingness to pay is affected by the total level of pollution linked with output production. If the prior attaches a bigger probability to the producer being clean, then it is more plausible that pooling equilibria result where clean and dirty producers act alike. The result that pooling equilibrium prices prevail over separating equilibrium prices contrasts with the standard result that high and low-quality producers always separate themselves, which has been emphasized in the literature of industrial organization. Clearly, the predictions of pooling behaviors rely highly on the equilibrium selection employed. In any undefeated pooling equilibrium, the uninformative price is distorted, respectively downward for the clean producer and upward 
for the dirty producer, relative to their full information price. Hence, the clean and the dirty producers pollute respectively more and less than under full information when consumers optimistically overestimate environmental performance

The emergence of pooling equilibria in the present context is potentially worrying due to its analogy with the "lemons" problem described by Akerlof (1970). A producer's incentive to adopt a technology that is both cleaner and more costly may be weakened if a clean product is expected to sell at the same price as a dirty product. Thus, under optimistic beliefs, the dirty products might drive out the clean ones in much the same way that bad cars drive out the good ones. This suggests that a producer must carefully take into account how his investment in a cleaner technology will affect the bias in price and the cost of signaling when he expects optimistic beliefs on his environmental performance. Nevertheless, the model developed here needs to be further extended in order to address the question of whether asymmetric information about environmental performance strengthens or weakens a producer's incentive to invest in a cleaner technology.

\section{Conclusion}

The present paper has investigated the pricing behavior of a polluting producer endowed with superior information about the environmental perfor- 
mance of his product. Separating price equilibria are shown to exist because a cleaner producer is more willing to raise price and reduce pollution. The price that signals a clean product is higher than the full information price. However, pooling price equilibria emerge as the most plausible ones when consumers optimistically estimate environmental performance before purchase. Under optimistic beliefs, the opportunity cost of signaling the true environmental performance is so high for the clean producer that he prefers choosing uninformative prices.

A noteworthy implication of these findings deals with government's intervention through the use of the Pigovian tax. While the Pigovian tax is the best way to correct the inefficiencies due to pollution when the market is perfectly competitive, it is no longer true when markets are imperfectly competitive. In the present context of asymmetric information, the use of a Pigovian fee might make matters even worse. Indeed, signaling tends to reduce output and emissions below the full information level. If a Pigovian tax were imposed to tackle the problem of pollution, output and emissions would be restricted even further. There is no obvious reason why such a policy should alone improve social welfare. In the present context, a benevolent regulator would be faced with three potential distortions: one is the distortion due to the externality, another one is the upward (downward) bias in price (production) associated with the exercise of monopoly power, and the third one is the informational distortion. Following Tinbergen (1956) and 
more recently Laffont (1994), one would require three policy instruments to achieve social efficiency. Thorough research is needed to address such a question.

Moreover, further empirical research is needed to estimate the size of the signaling distortions and the magnitude of the efficiency losses attributable to them. This may be a difficult issue to handle since it would require addressing the question of how to deal with full information prices which presumably are not observable. 


\section{Appendix}

\section{Appendix 1.}

Condition (4) can be rewritten

$$
(\varphi(\underline{\theta})-c(\bar{\theta}))\left(\frac{R-\varphi(\underline{\theta})}{1+\beta \underline{\theta}}\right)-\frac{(R-c(\bar{\theta}))^{2}}{4(1+\beta \bar{\theta})} \leq 0,
$$

which holds only for prices $\varphi(\underline{\theta})$ in the set

$\mathcal{P}_{1} \equiv[c(\bar{\theta}),[(R+c(\bar{\theta}))(1+\beta \bar{\theta})-(R-c(\bar{\theta})) \sqrt{\beta(\bar{\theta}-\underline{\theta})(1+\beta \bar{\theta})}] / 2(1+\beta \bar{\theta})]$

$\cup[[(R+c(\bar{\theta}))(1+\beta \bar{\theta})+(R-c(\bar{\theta})) \sqrt{\beta(\bar{\theta}-\underline{\theta})(1+\beta \bar{\theta})}] / 2(1+\beta \bar{\theta}), R]$, where

$\bar{p} \equiv[(R+c(\bar{\theta}))(1+\beta \bar{\theta})+(R-c(\bar{\theta})) \sqrt{\beta(\bar{\theta}-\underline{\theta})(1+\beta \bar{\theta})}] / 2(1+\beta \bar{\theta})$. Moreover, $R>c(\underline{\theta})$ implies that $\frac{(R-c(\bar{\theta}))^{2}}{4(1+\beta \bar{\theta})}>0$, hence the right-hand side of inequality

(4) is strictly positive. This guarantees that $\bar{p}<R$.

Appendix 2.

Condition (5) can be rewritten

$$
(\varphi(\underline{\theta})-c(\underline{\theta}))\left(\frac{R-\varphi(\underline{\theta})}{1+\beta \underline{\theta}}\right)-\frac{(R-c(\underline{\theta}))^{2}}{4(1+\beta \bar{\theta})}>0 .
$$

This inequality is met for prices $\varphi(\underline{\theta})$ in the interval

$$
\begin{aligned}
& \mathcal{P}_{2} \equiv([(R+c(\underline{\theta}))(1+\beta \bar{\theta})-(R-c(\underline{\theta})) \sqrt{\beta(\bar{\theta}-\underline{\theta})(1+\beta \bar{\theta})}] / 2(1+\beta \bar{\theta}), \\
& [(R+c(\underline{\theta}))(1+\beta \bar{\theta})+(R-c(\underline{\theta})) \sqrt{\beta(\bar{\theta}-\underline{\theta})(1+\beta \bar{\theta})}] / 2(1+\beta \bar{\theta})) .
\end{aligned}
$$

Further calculations allow to check that the set $\mathcal{P}_{1} \cap \mathcal{P}_{2}$ is non empty:

$$
\bar{p}-[(R+c(\underline{\theta}))(1+\beta \bar{\theta})+(R-c(\underline{\theta})) \sqrt{\beta(\bar{\theta}-\underline{\theta})(1+\beta \bar{\theta})}] / 2(1+\beta \bar{\theta})
$$




$$
=-(1+\beta \bar{\theta})(1+\beta \underline{\theta})<0 .
$$

\section{Appendix 3.}

The price distortion necessary to reveal high environmental performance can be expressed as follows

$$
\bar{p}-p^{*}(\underline{\theta})=[(c(\bar{\theta})-c(\underline{\theta}))(1+\beta \bar{\theta})+(R-c(\bar{\theta})) \sqrt{\beta(\bar{\theta}-\underline{\theta})(1+\beta \bar{\theta})}] / 2(1+\beta \bar{\theta}) .
$$




\section{References}

[1] AKERLOF, G. A. (1970), “The Market for 'Lemons': Qualitative Uncertainty and the Market Mechanism", Quarterly Journal of Economics $84,488-500$.

[2] ARORA, S. and GANGOPADHYAY S. (2003), "Toward a Theoretical Model of Voluntary Overcompliance", Journal of Economic Behavior and Organization 28, 289-309.

[3] BANSAL, S. and GANGOPADHYAY S. (2003), "Tax/Subsidy Policies in the Presence of Environmentally Aware Consumers", Journal of Environmental Economics and Management 45, 333-355.

[4] BAGWELL, K. and M. H. RIORDAN (1991), "High and Declining Prices Signal Product Quality", American Economic Review 81, 224239.

[5] BAUMOL, J. and W. E. OATES (1975), The Theory of Environmental Policy, Second Edition, Cambridge: Cambridge University Press.

[6] BOULDING, W. and A. KIRMANI (1993), "A Consumer-Side Experimental Examination of Signaling Theory: Do Consumers Perceive Warranties as Signals of Quality?", Journal of Consumer Research 20, 111123. 
[7] BUCHANAN, J. M. (1969), "External Diseconomies, Corrective Taxes and Market Structures", American Economic Review 59, 174-177.

[8] CASON T. N. and L. GANGADHARAN. (2002), "Environmental Labelling and Incomplete Consumer Information in Laboratory Experiments", Journal of Environmental Economics and Management 43, 113134.

[9] CREMER, H. and J.-F. THISSE (1999), “On the Taxation of Polluting Products in a Differentiated Industry", European Economic Review 43, $575-594$.

[10] FOULON J., P. LANOIE and B. LAPLANTE (2002), "Incentives for Pollution Control; Regulation or Information?", Journal of Environmental Economics and Management 44, 169-187.

[11] INNES R. and J. J. BIAL (2003), "Inducing Innovation in the Environmental Technology of Oligopolistic Firms", The Journal of Industrial Economics 3, 265-287.

[12] KOLSTAD, C. D. (2000), Environmental Economics, Oxford University Press.

[13] KOTCHEN, M. J. (2006), "Green Markets and Private Provision of Public Goods", Journal of Political Economy 114, 816-834. 
[14] LAFFONT, J.- J. (1994), "Regulation of Pollution with Asymmetric Information" in C. Dosi and T. Tomasi (eds), Nonpoint Source Pollution Regulation: Issues and Analysis, Dordrecht: Kluwer Academic Publishers, 39-66.

[15] MAILATH G. (1987), "Incentive Compatibility in Signaling Games with a Continuum of Types", Econometrica 55, 1349-1365.

[16] MAIlATH, G., M. OKUNO-FUJIWARA and A. POSTLEWAite (1993), "Belief-Based Refinements in Signaling Games", Journal of Economic Theory 60, 241-276.

[17] MILGROM P. and J. ROBERTS (1986), "Price and Advertising Signals of Product Quality", Journal of Political Economy 94, 796-821.

[18] NIMON, W. and J. BEGHIN (1999), "Are Eco-labels Valuable? Evidence from the Apparel Industry", American Journal of Agricultural Economics 81, 801-811.

[19] SPENCE, A. M. (1976), "Informational Aspects of Market Structure: An Introduction", Quarterly Journal of Economics 90, 591-597.

[20] TIETENBERG, T. (2000), Environmental and Natural Resource Economics, Addison Wesley Longman, Inc., fifth edition.

[21] TINBERGEN, J. (1956), Economic Policy: Principles and Design. Amsterdam: North-Holland. 
[22] TIROLE, J. (1988), The theory of Industrial Organization. Cambridge, Mass.: MIT Press. 